\title{
A Demographic Study of Thoracolumbar Junction Fracture in a Developing Country and its Social Impact
}

\author{
Dewan Shamsul Asif ${ }^{1}$, Paawan Bahadur Bhandari², Sader Hossain SK ${ }^{3}$ and Asifur Rahman ${ }^{4 *}$ \\ ${ }^{1}$ Resident, Department of Neurosurgery, Bangabandhu Sheikh Mujib Medical University, Bangladesh \\ ${ }^{2}$ Department of Neurosurgery, Bangabandhu Sheikh Mujib Medical University, Kazi Nazrul Islam Avenue, Bangladesh \\ ${ }^{3}$ Professor, Department of Neurosurgery, Dhaka Medical College and Hospital, Bangladesh \\ ${ }^{4}$ Assistant Professor, Department of Neurosurgery, Bangabandhu Sheikh Mujib Medical University, Bangladesh
}

\begin{abstract}
Introduction: Spinal cord injury due to traumatic accidents is a major cause of disability throughout the world. Among the spinal injury patients more than $30 \%$ suffered from Thoracolumbar Spine (TLS) injury with great preponderance to Thoracolumbar Junction (T10-L2) injury. Delay or inappropriate management of these patients leads to a great socio-economical impact on the society.
\end{abstract}

Methods and materials: This was a prospective study on 38 patients who were admitted in the Neurosurgery Department at Dhaka Medical College and Hospital (DMCH) in the period of January 2010 to December 2011 with thoracolumbar junction injuries and were analyzed regarding demographic patterns after getting approval of the Ethical Committee of Bangladesh College of Physician and Surgeons (BCPS) and DMCH. Patients with single level Thoracolumbar Junction Injury (D10-L2) and who had TLICS score $\geq 4$ were included in this study. Patients with TLICS score $\leq 3$, multiple level thoracolumbar junction injury, associated other injuries like head injury, abdominal injury, long bone fractures and any pathological thoracolumbar fractures were excluded.

Result: There were 36 males and 2 females with average age of $29.42 \pm 8.11$ years (range 17-50 years). Fall from height was the commonest $(79 \%)$ cause of injury. Most of the patients were farmers and came from lower income class. Most of the patients $29(76.3 \%)$ were illiterate. The mean time interval from injury to admission was found to be $8.97 \pm 10.11$ days ( 2 to 60 days).

Conclusion: In this study large number of patients was in their active period of life. Due to lack of awareness in their working place, proper counseling and appropriate management of these patients eventually become burden to their family and society. This burden can be minimized with good governance regarding safety measurement in working place and raising awareness among people in their active lives.

Keywords: Thoracolumbar junction fracture; Demographic study; Social impact

\section{Introduction}

Spinal cord injury due to traumatic accidents of the thoracolumbar spine is a major cause of disability throughout the world [1]. Thoracolumbar fractures are associated with a high incidence of neurological injuries because of the significant kinetic energy required to create these lesions. The transfer of axial loads through the transition from the rigid thoracic kyphosis to the mobile lumbar region results in a high incidence of thoracolumbar junction injuries [2].

Developing country like Bangladesh is at high risk of this kind of injuries as because there seems to be unawareness of safety program in the work places and, in addition, socioeconomic condition and illiteracy plays an important role.

In the year 2009 total number of patients with spinal injury admitted at Dhaka Medical College Hospital (DMCH) were 236. Among those $69.9 \%$ and $31.1 \%$ were cervical spine injury and Thoracolumbar Spine (TLS) injuries respectively which leads to large number of working population to become disabled and eventually a burden to the society. Moreover the health care system of this country does not provide any short or long term support to the patient which eventually has to be managed by his/her family which leads to tremendous social and economic impact on the affected family.

Keeping this background in mind we analyzed a small number of patients to find out the mechanism of injury and its social and cultural backgrounds as well as its impact to their current living condition.

\section{Materials and Methods}

This was a prospective study on 38 patients who were admitted in the Neurosurgery Department at DMCH in the period of January 2010 to December 2011 with thoracolumbar junction injuries and were analyzed regarding demographic patterns. Patients with single level Thoracolumbar Junction Injury (D10-L2) and who had TLICS score $\geq 4$ were included in this study as they eventually underwent surgical procedure. Exclusion criteria were Patients with TLICS score $\leq 3$, multiple level thoracolumbar junction injury, associated other injuries like head injury, abdominal injury, long bone fractures and any pathological thoracolumbar fractures. Prior to the commencement of this study, the research protocol had been approved by the Ethical Committee of Bangladesh College of Physician and Surgeons (BCPS) and $\mathrm{DMCH}$. Categorical data had been presented as frequency, percentage and continuous variable presented as mean and standard deviation.

*Corresponding author: Asifur Rahman, Assistant Professor, Department of Neurosurgery, Bangabandhu Sheikh Mujib Medical University, Kazi Nazrul Islam Avenue, Shahbag, Dhaka 1000, Bangladesh, Tel: 008801819463005; E-mail: bijoun14@yahoo.com

Received July 26, 2013; Accepted August 23, 2013; Published August 26, 2013

Citation: Asif DS, Bhandari PB, Sader Hossain SK, Rahman A(2013) A Demographic Study of Thoracolumbar Junction Fracture in a Developing Country and its Social Impact. J Spine 2: 141. doi:10.4172/2165-7939.1000141

Copyright: (c) 2013 Rahman A, et al. This is an open-access article distributed under the terms of the Creative Commons Attribution License, which permits unrestricted use, distribution, and reproduction in any medium, provided the original author and source are credited. 
Citation: Asif DS, Bhandari PB, Sader Hossain SK, Rahman A (2013) A Demographic Study of Thoracolumbar Junction Fracture in a Developing Country and its Social Impact. J Spine 2: 141. doi:10.4172/2165-7939.1000141

Page 2 of 4

\section{Results}

A total of 38 patients were included in this study. They were divided into seven groups according to their age (Table 1). Majority $11(28.9 \%)$ of the patients belonged to 21-25 years age group. The mean age was $29.42 \pm 8.11$ years with range from 17 to 50 years. Thirty-six $(94.7 \%)$ study patients were male and $2(5.3 \%)$ were female with a male to female ratio of 18:1 (Table 2).

Majority, $21(55.3 \%)$ patients were farmers, followed by $12(31.6 \%)$ day laborers, $2(5.3 \%)$ industrial workers, $2(5.3 \%)$ housewives and, $1(2.6 \%)$ tailor (Table 3$)$. Majority $27(71.1 \%)$ patients came from lower socio-economic class and the rest $11(28.9 \%)$ came from lower middle class group (Table 4$)$. Twenty-nine $(76.3 \%)$ of our patients were illiterate, $8(21.1 \%)$ of the patients had primary level education and, 1 (2.6\%) of the patients had a high-school diploma (Table 5).

In $30(79 \%)$ patients, injury was caused by fall from height and in the remaining $8(21 \%)$ patients the mode of injury was road traffic accident [RTA] (Table 6). Among the patients who fell from height; $19(50 \%)$ of patients had fall on their buttock, 8 (21.1\%) of the patients had fall on their back and $3(7.9 \%)$ of the patients had fall on their feet. Among the RTA group; 4 (10.5\%) of the patients were pedestrians and $4(10.5 \%)$ were passengers.

On admission all 38 patients had neurological deficit (Table 7). There were $2(5.3 \%)$ patients with ASIA grade A, 3 (7.9\%) patients with ASIA grade B, 27 (71.1\%) patients with ASIA grade C and $6(15.8 \%)$ patients with ASIA grade D levels of neurological deficit.

The mean time interval from injury to admission was found 8.97

\begin{tabular}{|c|c|c|}
\hline Age (years) & Number of patients & Percentage \\
\hline $15-20$ & 5 & 13.2 \\
\hline $21-25$ & 11 & 28.9 \\
\hline $26-30$ & 9 & 23.7 \\
\hline $31-35$ & 7 & 18.4 \\
\hline $36-40$ & 2 & 5.3 \\
\hline $41-45$ & 3 & 7.9 \\
\hline $46-50$ & 1 & 2.6 \\
\hline Mean \pm SD & 29.42 & \pm 8.11 \\
\hline Range (min-max) & $(17$ & $-50)$ \\
\hline
\end{tabular}

Table 1: Age distribution of the study patients $(n=38)$

\begin{tabular}{|c|c|c|}
\hline Sex & Number of patients & Percentage \\
\hline Male & 36 & 94.7 \\
\hline Female & 2 & 5.3 \\
\hline
\end{tabular}

Table 2: Sex distribution of the study patients $(n=38)$.

\begin{tabular}{|c|c|c|}
\hline Occupation & Number of patients & Percentage \\
\hline Farmer & 21 & 55.3 \\
\hline Day labor & 12 & 31.6 \\
\hline Industrial worker & 2 & 5.3 \\
\hline House wife & 2 & 5.3 \\
\hline Tailor & 1 & 2.6 \\
\hline
\end{tabular}

Table 3: Occupational status of the study patients $(n=38)$.

\begin{tabular}{|l|c|c|}
\hline Socioeconomic status & $\begin{array}{c}\text { Number of } \\
\text { patients }\end{array}$ & Percentage \\
\hline $\begin{array}{l}\text { Lower income class } \\
(<5000 \text { BDT/month, approximately \$65) }\end{array}$ & 27 & 71.1 \\
\hline $\begin{array}{l}\text { Lower middle income class } \\
(5000-20000 \text { BDT/month, approximately \$65-\$250) }\end{array}$ & 11 & 28.9 \\
\hline
\end{tabular}

Table 4: Socioeconomic status of the study patients $(n=38)$.

\begin{tabular}{|c|c|c|}
\hline Education & Number of patients & Percentage \\
\hline Illiterate & 29 & 76.3 \\
\hline Primary & 8 & 21.1 \\
\hline High-school Diploma & 1 & 2.6 \\
\hline
\end{tabular}

Table 5: Educational status of the study patients $(n=38)$.

\begin{tabular}{|c|c|c|}
\hline Mode of injury & Number of patients & Percentage \\
\hline Vehicle accident & 4 & 10.5 \\
\hline Pedestrian & 4 & 10.5 \\
\hline Passenger & \multicolumn{2}{|c|}{} \\
\hline Fall from height & 3 & 7.9 \\
\hline On feet & 8 & 21.1 \\
\hline On back & 19 & 50 \\
\hline On buttock & & \\
\hline
\end{tabular}

Table 6: Distribution of the study patients according to mode of injury $(n=38)$.

\begin{tabular}{|c|c|c|}
\hline ASIA impairments scale & Number of patients & Percentage \\
\hline A & 2 & 5.3 \\
\hline B & 3 & 7.9 \\
\hline C & 27 & 71.1 \\
\hline D & 6 & 15.8 \\
\hline E & 0 & 0 \\
\hline
\end{tabular}

Table 7: Distribution of the study patients according to ASIA impairment scale $(n=38)$.

\begin{tabular}{|c|c|c|}
\hline Time interval & Mean \pm SD & Range (min-max) \\
\hline Injury to admission (day) & $8.97 \pm 10.11$ & $(2-60)$ \\
\hline Admission to operation (day) & $24.03 \pm 14.42$ & $(4-62)$ \\
\hline Injury to operation (day) & $33.00 \pm 17.3$ & $(7-82)$ \\
\hline $\begin{array}{c}\text { Post-operative hospital stay } \\
\text { (day) }\end{array}$ & $24.68 \pm 8.26$ & $(10-38)$ \\
\hline
\end{tabular}

Table 8: Mean distribution of the study patients according to different time intervals $(n=38)$.

\pm 10.11 days ( 2 to 60 days) (Table 8 ). The mean time interval from admission to surgery was $24.03 \pm 14.42$ days ( 4 to 62 days). The mean time interval from operation to discharge was $24.68 \pm 8.26$ days (10 to 38 days). And, the mean time interval from injury to operation was $33.0 \pm 17.3$ days ( 7 to 82 days).

\section{Discussion}

Traumatic spinal injury is common in our country in young, predominantly male patients in good health; which is reflected in this study as the mean age of patients were $29.42 \pm 8.11$ years (range 17-50 years). Majority 27 (71\%) of the patients belonged to the $21-35$ years age group. Kong et al. [3] in their study reported mean age of patients to be $29.5 \pm 8.6$ years (range 23-49 years). Nasser and Gawad [4] reported in their study mean age of patients to be 28.8 years (range $16-49$ years). These studies correlate practically with the current one. In the context of this country, by social and cultural norms, if the patient is the only earning member of family with at least 4-5 dependent persons on him/ her, this kind of injury if not properly addressed will eventually have profound effect on socioeconomic aspect of the society.

On the other hand Arif et al. [5] reported in their study the mean age of the patients was 32 years (range 20-65 years). Butt et al. [1] reported in their study mean age of the patients 33 years (range 20-40 years). Butt et al. [6] reported in their study mean age 33.6 years (range 20-50 years). Knop et al. [7] reported mean age 34 years (range 15-65 years). Benzel [8] reported mean age 36 years(range 15-57 years). Danisa et al. [9] reported mean age age of patients to be 36.6 years (range 13-75 years). Tezer et al. [10] reported mean age to be 39 years (range 23-62 
years). Khan et al. [11] showed mean age $40 \pm 13.75$ years (range 15-60 years). In their study, Siebenga et al. [12] found mean age to be 45.7 years (range 27-59 years). Mean age of these studies were somewhat higher. As most of these studies were done in developed countries, it might be so as in comparison to developing country like ours their life expectancy is more and their active life is more than ours.

In this study there were $36(94.7 \%)$ males and $2(5.3 \%)$ females. Male and female ratio was 18:1. By occupation 21(55.3\%) were farmers, 12(31.6\%) were day labourers, $2(5.3 \%)$ were industrial workers, 2 (5.3\%) were housewives and $1(2.6 \%)$ was a tailor. As most of these occupations are related to male predominant sectors, it seemed to be a male predominant study, which also reflects the current trends of our country's social and cultural norms of male predominant hard labour activity. Nasser and Gawad [4] reported in their study 33 males and 4 females. Butt et al. [1] reported in their study 93 males and 34 females. Like these studies Benzel [8], Knop et al. [7], Kong et al. [3], Khan et al. [11], Butt et al. [6], Arif et al. [5], Tezer et al. [10], Siebenga et al. [12] and Danisa et al. [9] described male predominant studies.

In this study, it was observed that among the modes of injuries, fall from height [FFH] were in 30(79\%) patients and road traffic accidents were [RTA] in $8(21 \%)$ patients. Butt et al. [6] reported in their study most common cause was fall from height, usually from a tree. Butt et al. [1] in another study reported $90 \%$ cause was fall from height. Nasser and Gawad [4], Kong et al. [3], Knop et al. [7] and Siebenga et al. [12] also reported in their studies FFH as the major of cause of injury. But Arif et al. [5], Tezer et al. [10] and Danisa et al. [9] reported RTA as the major cause of injury in their studies. Nearly half of the spinal injuries result from motor vehicle accidents and from fall from height in the developed countries, whereas the bulk of the spinal injuries in the developing countries is due to fall from height. All of the patients in this study fell from height during their work time which is definitely preventable if proper awareness measures were taken. The lack of specialist treatment and poor rehabilitation facilities in the poorer countries makes life miserable for the patients with neurological deficit. There is a need for community education to prevent or at least minimize the incidence of such injuries. In Kashmir, for example, $80 \%$ of spinal injuries occurred due to fall from trees during fruit season [autumn] as reported by Butt et al. [6]. The role of an independent prevention unit as advocated by Toscano [13] would be of tremendous significance in our circumstances in educating the general public, paramedics, nursing staff, and medical practitioners about traumatic cord paralysis. This would minimize the trauma level; improve referral, transportation, and post-op rehabilitation of injured ones.

In this study $29(76.3 \%)$ patients were illiterate, $8(21.1 \%)$ patients had primary level education and 1 (2.6\%) patient had secondary school certificate level education where the average literacy rate of the country is $56.8 \%$ [http://www.indexmundi.com/bangladesh/literacy.html]. And socioeconomic study showed majority $27(71.1 \%)$ came from lower income class group $(<5000 \mathrm{BDT} /$ month, approximately $\$ 65)$ and rest 11 (28.9\%) were from lower middle income class group (5000-20000 $\mathrm{BDT} /$ month, approximately $\$ 65-\$ 250)$. So majority of the patients belong to very poor class as they are even below per capita, which is $\$ 1700$ per year [14]. And also we have to keep in mind that he or she is the only earning member of family and eventually every family member is dependent on him. This reflected that occupational reintegration is an important challenging management issue considering the relatively young patient with average age of 29 years and low income group. The socioeconomic impact of this type of injury is significant. In a study of developed country by Knop et al. [7] an incomplete occupational reintegration was noted in their patient population.
In the current study the mean time interval from injury to admission was $8.97 \pm 10.11$ days (range 2-60 days). The mean time interval of surgery after admission was $24.03 \pm 14.42$ days (range 4-62 days). As a result the mean time interval of surgery after injury was $33.00 \pm 17.3$ days (range 7-82 days). Knop et al. [7] reported mean time from injury to surgery was 6 days. This reflects that there was lack of awareness among the general public and health care providers about traumatic cord paralysis. In this study there was significant delay in referring patient to hospital. Even after admission due to unavailability of operation schedule as a result of overburden patients of various types of injuries, we could not perform surgery earlier than we had done. Neurological recovery has been reported with early stabilisation of thoracolumbar spinal fractures by Gaebler et al. [15]. The highest recovery rates have been reported for patients operated on within 8 $\mathrm{h}$ of the initial trauma, while high remission rates have been reported for patients operated on within $48 \mathrm{~h}$ of the initial trauma. After this time there is no significant difference in the neurological outcome with respect to the timing of operation after the trauma. The earliest we were able to stabilize a spine was 7 days after the initial trauma-primarily because of the non-availability of facilities for emergency stabilization of the spine in our setup. The pattern of neurological recovery in our patients, however, was encouraging despite this delay.

\section{Conclusion}

Though there is a bulk of patients who are admitted with spinal injury that can lead to long term disability, there is yet any study addressing this issue. So this is study was design with a small population to assess the 'tip of the iceberg' of this grave condition and its socioeconomic impact.

This study clearly shows that large numbers of patients were in their active period of life. Due to unawareness in their working place they were vulnerable to injury. And also this study depicts that their illiteracy also plays important role. If this group of people are not properly addressed they eventually become burden to their family and also to the society. As prevention is better than cure, good governance regarding safety measurement in working place and awareness among people of their active life plays an important role. So our recommendation to health care system is to take proper measures for safety of workers along with further large cohort study should be undertaken get the full picture of the iceberg.

\section{References}

1. Butt MF, Dhar SA, Farooq M, Hussain A, Mir BA, Halwai MA, et al. (2008) Neurological outcome following delayed fixation of unstable thoracolumbar spinal injuries with short segment posterior fixation. Neurosciences 13: 65-69.

2. Marchan E, Vaccaro AR, Foley KT, Kalfas IH, Harrop JS (2012) Trauma Surgery: Thoracic and Thorcolumbar Spine. (3rdedn), Benzel EC, Philadelphia, USA.

3. Kong W, Sun Y, Hu J, Xu J (2010) Modified posterior decompression for the management of thoracolumbar burst fractures with canal encroachment. J Spinal Disord Tech 23: 302-309.

4. Nasser M, Gawad A (2001) Posterior pedicle screw instrumentation for management of unstable thoracolumbar spine injuries. Pan Arab J Orth Trauma 5: 29-40.

5. Arif M, Inam M, Satar A, Saeed M, Shabir M (2009) Management of thoracolumbar spinal fractures by pedicular screws and rods. Gomal Journal of Medical Sciences 7: 109-113.

6. Butt MF, Farooq M, Mir B, Dhar AS, Hussain A, et al. (2007) Management of unstable thoracolumbar spinal injuries by posterior short segment spinal fixation. Int Orthop 31: 259-264.

7. Knop C, Fabian HF, Bastian L, Blauth M (2001) Late results of thoracolumba fractures after posterior instrumentation and transpedicular bone grafting. Spine 26: 88-99. 
Citation: Asif DS, Bhandari PB, Sader Hossain SK, Rahman A (2013) A Demographic Study of Thoracolumbar Junction Fracture in a Developing Country and its Social Impact. J Spine 2: 141. doi:10.4172/2165-7939.1000141

8. Benzel EC (1993) Short-segment compression instrumentation for selected thoracic and lumbar spine fractures: the short-rod/two-claw technique. $J$ Neurosurg 79: 335-340.

9. Danisa OA, Shaffrey CI, Jane JA, Whitehill R, Wang GJ, et al. (1995) Surgical approaches for the correction of unstable thoracolumbar burst fractures: a retrospective analysis of treatment outcomes. J Neurosurg 83: 977-983.

10. Tezer M, Ozturk C, Aydogan M, Mirzanli C, Talu U, et al. (2005) Surgical outcome of thoracolumbar burst fractures with flexion-distraction injury of the posterior elements. Int Orthop 29: 347-350.

11. Khan AA, Khanzada K, Ayub S, Ali M (2008) Surgical outcome of transpedicular fixation in thoracolumber fractures. J Ayub Med Coll Abbottabad 20: 104-107.
12. Siebenga J, Leferink VJ, Segers MJ, Elzinga MJ, Bakker FC, et al. (2006) Treatment of traumatic thoracolumbar spine fractures: a multicenter prospective randomized study of operative versus nonsurgical treatment. Spine 31: 2881 2890.

13. Toscano J (1988) Prevention of neurological deterioration before admission to a spinal cord injury unit. Paraplegia 26: $143-150$.

14. http://www.indexmundi.com/g/g.aspx?v=67\&c=bg\&l=en

15. Gaebler C, Maier R, Kutscha-Lissberg F, Mrkonjic L, Vecsei V (1999) Results of spinal cord decompression and thoracolumbar pedicle stabilisation in relation to the time of operation. Spinal Cord 37: 33-39. 